\title{
Substance $P$ prevents doxorubicin-induced cardiomyocyte injury by regulating apoptosis and autophagy: In vitro and in vivo evidence
}

\author{
FA-XIU CHEN, QIN WAN, QING-LING LI, JING FANG, LE PENG and JIAN HU \\ Department of Geriatrics and Gerontology, People's Hospital Affiliated to \\ Nanchang University, Nanchang, Jiangxi 330006, P.R. China
}

Received May 5, 2021; Accepted August 8, 2021

DOI: $10.3892 / \mathrm{mmr} .2021 .12566$

\begin{abstract}
The function of substance P (SP) in myocardial ischemia is well understood, but its effects on congestive heart failure are unclear. The present study aimed to use in vitro and in vivo approaches to investigate the effects of SP on doxorubicin-induced cardiomyocyte injury. Pathological changes, apoptosis, cardiomyocyte ultrastructure and molecular mechanisms were evaluated in vitro and in vivo. The effects of SP on cell viability of H9c2 myocardial cells were evaluated using the Cell Counting Kit- 8 and flow cytometry. B-cell lymphoma 2 (Bcl-2), Bcl-2-associated X protein (Bax), Beclin-1 and microtubule-associated protein 1A/1B-light chain 3 (LC3) were detected by western blotting. Heart failure in rats was established by intraperitoneal injection of doxorubicin. The in vitro data demonstrated that SP at concentrations of $1 \mu \mathrm{g} / \mathrm{ml}$ inhibited doxorubicin-induced apoptosis of $\mathrm{H} 9 \mathrm{c} 2$ cells. Administration of doxorubicin reduced Bcl-2, Beclin-1 and LC3 expression levels in $\mathrm{H} 9 \mathrm{c} 2$ cells, while having no effect on Bax levels. Administration of SP to these doxorubicin-treated cells did not affect Bcl-2 or Bax expression, but further reduced Beclin-1 while inhibiting the reduction in LC3 expression. In vivo, food intake was significantly increased in rats in the SP group compared with the model group. Cardiomyocytes in the heart-failure group underwent dysfunctional autophagy as ascertained by transmission electron microscopy. Compared with the heart-failure group, these pathological changes, including loss of striations and vacuolation, were inhibited by SP treatment, which promoted Bax expression, reduced Beclin-1 expression and inhibited the reduction in LC3 expression. Taken together, SP reduced cardiomyocyte apoptosis in doxorubicin-induced cardiomyocyte injury, likely by promoting autophagy, which suggested
\end{abstract}

Correspondence to: Dr Jian Hu, Department of Geriatrics and Gerontology, People's Hospital Affiliated to Nanchang University, 152 Aiguo Road, Nanchang, Jiangxi 330006, P.R. China E-mail: huyidao9989@163.com

Key words: substance $\mathrm{P}$, heart failure, autophagy, apoptosis that SP is a potential therapeutic target for doxorubicin-induced heart failure.

\section{Introduction}

Doxorubicin is one of the most widely used chemotherapeutic drugs (1), which acts primarily by triggering apoptosis via inhibition of topoisomerase activity and generation of reactive oxygen species (ROS) (2). Cardiotoxicity and congestive heart failure (CHF) are prominent side effects of doxorubicin because of its toxic effects on cardiomyocytes (3) and this limits its clinical use. Notably, doxorubicin is widely used to produce animal and cellular models of heart failure $(4,5)$. Apoptosis is known to be one of the key pathological processes of CHF (6); therefore, a strategy to prevent cardiomyocyte apoptosis could effectively delay and treat CHF (7).

Substance P (SP) belongs to the tachykinin family of sensory neuropeptides, which serves an important role in activating tachykinin receptor 1 . SP functions in the repair of sensory injury, regulation of smooth muscle contraction and modulation of inflammation/immune responses (8-12). SP is mainly expressed in the central nervous system and peripheral afferent sensory neurons, especially in C-fibers (13). In addition to neurons, SP is also found in heart tissue (14). Expression of SP has been reported to markedly increase following ischemic injury, which SP has previously been shown to limit $(15,16)$. In addition, SP is hypothesized to promote inflammation and cardiac hypertrophy in myocarditis $(17,18)$. SP may also be involved in heart failure caused by hypertension or stress by promoting expression of MMPs (19). However, the effects of SP on doxorubicin-induced heart failure remain to be elucidated.

Autophagy is one type of cellular degradation, which functions to remove unnecessary or damaged components $(20,21)$. Inappropriate autophagy is associated with several diseases, including cardiac and neurodegenerative diseases (22). The present study used cellular and animal experiments to investigate the effects of SP on cardiomyocyte injury caused by doxorubicin. Additionally, the potential mechanisms involving autophagy were investigated. The data demonstrated that SP limited doxorubicin-induced cardiomyocyte injury, probably by regulating apoptosis and autophagy. These results have 
implications for the prevention of doxorubicin-induced heart failure.

\section{Materials and methods}

Ethics statement. The animal protocols performed in the present study were approved by the Ethics Committee of People's Hospital Affiliated to Nanchang University (Nanchang, China; approval no. 2019-037). After the experiments, animals were anesthetized by $5 \%$ isoflurane, followed by decapitation.

Cell culture and treatments. H9c2 myocardial cells were purchased from BeNa Culture Collection (Beijing Beina Chunglian Institute of Biotechnology; cat. no. BNCC295057) and were cultured in Dulbecco's modified Eagle's medium (Gibco; Thermo Fisher Scientific, Inc.) supplemented with 10\% FBS (Gibco; Thermo Fisher Scientific, Inc.) in an incubator with $5 \% \mathrm{CO}_{2}$ at $37^{\circ} \mathrm{C}$. The effects of SP on the viability of $\mathrm{H} 9 \mathrm{c} 2$ cells were determined using the Cell Counting Kit-8 (CCK-8) assay (Beyotime Institute of Biotechnology). The protective effects of SP on doxorubicin-induced cell injury were evaluated as follows: After cells had adhered to the substrate, culture medium was discarded and the cells were washed with $1 \mathrm{X}$ phosphate buffered saline (PBS). Doxorubicin $(2 \mu \mathrm{M}$; cat. no. D107159; Shanghai Aladdin Biochemical Technology Co., Ltd.; model group) or $2 \mu \mathrm{M}$ doxorubicin $+1 \mu \mathrm{g} / \mathrm{ml}$ exogenous SP (cat. no. HY-P0201A; MedChemExpress) medium (SP group) were then added to paired wells; after $24 \mathrm{~h}$ at $37^{\circ} \mathrm{C}$, flow cytometry and western blotting were performed. The cells in the control group did not receive any treatment.

CCK-8 assay. After H9c2 cells had completely adhered to the well, the supernatant was discarded and different concentrations of SP $(0,0.1,0.5,1,5$ and $10 \mu \mathrm{g} / \mathrm{ml})$ suspended in fresh culture medium were added to the cells. The cells were cultured in an incubator at $37^{\circ} \mathrm{C}$ for $24 \mathrm{~h}$ and cell viability was assessed to screen for safe concentrations of SP. Briefly, following treatment, $10 \mu \mathrm{l}$ CCK-8 solution was added to each well and incubated at $37^{\circ} \mathrm{C}$ for $1.5 \mathrm{~h}$. Optical density was measured at a $450 \mathrm{~nm}$ using a microplate reader to calculate cell viability at each SP concentration and $1 \mu \mathrm{g} / \mathrm{ml}$ SP was selected to investigate its effect on doxorubicin-induced cardiomyocyte injury.

Flow cytometry. Following treatment for $24 \mathrm{~h}$, cells were collected, washed with PBS and centrifuged at $897 \mathrm{x}$ g for $3 \mathrm{~min}$ at $4^{\circ} \mathrm{C}$. Annexin V-fluorescein isothiocyanate $(3 \mu \mathrm{l})$ and propidium iodide $(5 \mu \mathrm{l})$ were added to the cells according to the instructions of the assay kit (cat. no. C1062S; Beyotime Institute of Biotechnology). After gentle mixing, the cells were incubated at room temperature for $10 \mathrm{~min}$ in the dark and apoptosis was measured by flow cytometry (NovoCyte ${ }^{\circledR} 2060$ R; ACEA Biosciences, Inc.) and analyzed using FlowJo 7.6 (FlowJo, LLC), The percentage of early + late apoptotic cells were counted.

Preparation of a heart-failure model and treatments. A total of 18 male Sprague Dawley rats (age, 2 months; weight, $200 \pm 20 \mathrm{~g}$ ) were purchased from Hunan Slake Jingda Experimental Animal Co., Ltd. [license no. SCXK
(Xiang) 2019-0004]. The animals were housed in a specific pathogen-free condition that was automatically maintained at a temperature of $23 \pm 2{ }^{\circ} \mathrm{C}$, a relative humidity of $45-65 \%$, and with a controlled $12 \mathrm{~h}$ light/dark cycle and free to access to food and water. The animals were divided into three groups (n=6/group): i) Control group; ii) model group; and iii) SP treatment group. The heart-failure rat model was prepared as previously described (23). Briefly, doxorubicin was injected intraperitoneally once every 3 days $(3 \mathrm{mg} / \mathrm{kg}$ ) with a cumulative total of $15 \mathrm{mg} / \mathrm{kg}$. The injections were completed within 2 weeks to establish the rat myocardial injury model. SP was injected via the caudal vein at a dose of $6.7 \mu \mathrm{g} / \mathrm{kg}$ once every 4 days as previously described (24). The rats in the control and model groups were injected with the same amount of saline. An electrocardiogram (ECG) was used to monitor heart function after treatment and heart rate was automatically recorded. Thereafter, the rats were decapitated following anesthesia (5\% isoflurane). Myocardial tissue was collected and fixed in $4 \%$ paraformaldehyde at $4^{\circ} \mathrm{C}$ overnight for determination of pathological changes.

Hematoxylin and eosin $(H \& E)$ staining. Fixed tissue was washed with running water for several hours, serially dehydrated in 70, 80 and 90\% ethanol, a mixture of ethanol and xylene for $15 \mathrm{~min}$, and then xylene for $30 \mathrm{~min}$. The tissues were subsequently immersed in a mixture of xylene and paraffin for $15 \mathrm{~min}$, and then in paraffin for 50-60 min. The paraffin-embedded tissues were then sectioned $(10 \mu \mathrm{m})$. After warming, dewaxing and rehydrating, the sections were stained with hematoxylin (3\%) and eosin (3\%) for $5 \mathrm{~min}$ at room temperature. The sections were observed under a light microscope (BX53, Olympus Corporation).

Terminal deoxynucleotidyl transferase dUTP nick end labeling (TUNEL) assay. After dewaxing (xylene treatment for $10 \mathrm{~min}$ ) and rehydrating in a gradient ethanol series at room temperature, $50 \mu \mathrm{g} / \mathrm{ml}$ proteinase $\mathrm{K}$ was added and the sections were incubated at $37^{\circ} \mathrm{C}$ for $30 \mathrm{~min}$. The tissues were then washed with PBS three times ( $5 \mathrm{~min} /$ wash). The PBS was removed and TUNEL solution $(5 \mu \mathrm{l} / \mathrm{ml}$; Beyotime Institute of Biotechnology) was added to each slide and incubated at $45^{\circ} \mathrm{C}$ for $2 \mathrm{~h}$ in the dark, followed by DAPI $(5 \mu \mathrm{g} / \mathrm{ml})$ staining at room temperature for $5 \mathrm{~min}$. The liquid on the slide was dried using absorbent paper and the slide was sealed and observed under a fluorescence microscope.

Transmission electron microscopy (TEM). Myocardial tissues were placed in $2.5 \%$ glutaraldehyde at $4^{\circ} \mathrm{C}$ for $4 \mathrm{~h}$ followed by fixation with $1 \%$ osmium tetroxide for $1.5 \mathrm{~h}$. and washed three times with pre-cooled PBS. After dehydration with a gradient ethanol series and acetone, the tissues were incubated in epoxy resin overnight at room temperature prior to sectioning $(2 \mathrm{~nm}$ slices). After that, the slices were stained with $2 \%$ uranyl acetate and $0.5 \%$ lead citrate for $5 \mathrm{~min}$ at room temperature. Autophagic ultrastructure was observed by transmission electron microscopy (HT7700; Hitachi High-Technologies Corporation; magnification, $\mathrm{x} 8,000)$.

Western blotting. Myocardial tissue was ground into powder in liquid nitrogen. Proteins were extracted from tissues and 


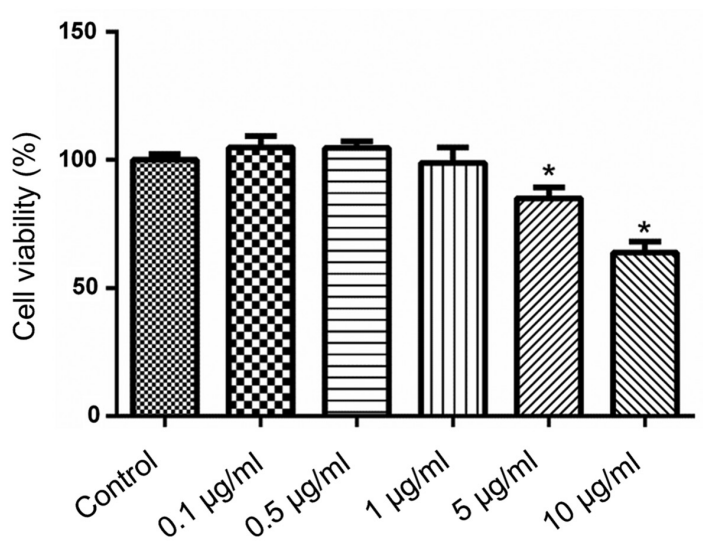

Figure 1. Effects of SP on the viability of H9c2 cells. SP at concentrations ranging from 0.1 to $1 \mu \mathrm{g} / \mathrm{ml}$ did not affect the viability of $\mathrm{H} 9 \mathrm{c} 2$ cells. By contrast, 5 or $10 \mu \mathrm{g} / \mathrm{ml} \mathrm{SP}$ reduced cell viability. ${ }^{*} \mathrm{P}<0.05$ vs. control cells ( $\mathrm{n}=6$ repeats/group). SP, substance $\mathrm{P}$.

H9c2 cells using a protein isolation kit (cat. no. 28-9425-44; Cytiva) and protein concentration was determined by the bicinchoninic acid method. The proteins $(25 \mu \mathrm{g} / \mathrm{lane})$ were denatured and separated by sodium dodecyl sulfate polyacrylamide gel electrophoresis for $2 \mathrm{~h}(12 \%$ gel), followed by transfer to a nitrocellulose membrane $(300 \mathrm{~mA}$ was applied for $80 \mathrm{~min})$ as described previously $(25,26)$. The membranes were blocked in 5\% skimmed milk for $2 \mathrm{~h}$ at room temperature. Thereafter, the membrane was incubated with primary antibodies at $4^{\circ} \mathrm{C}$ overnight, and then after washing, the membrane was incubated with a secondary antibody (horseradish peroxidase-labeled goat anti-rabbit IgG; 1:100; cat. no. ab6721; Abcam) at room temperature for $2 \mathrm{~h}$. Dye solution from an enhanced chemiluminescence kit (cat. no. RPN2133; Cytiva) was added to the membrane and staining was visualized using a gel imaging system (Bio-Rad Laboratories, Inc.). The gray value was analyzed by Quantity One software (version 4.62; Bio-Rad Laboratories, Inc.). The primary antibodies included mouse monoclonal anti- $\beta$-actin (1:2,000; cat. no. TA-09; OriGene Technologies, Inc.), mouse anti-B-cell lymphoma 2 (Bcl-2; 1:500; cat. no. ab692; Abcam), rabbit anti-Bcl-2-associated $\mathrm{X}$ protein (Bax; 1:500; cat. no. A0207; ABclonal Biotech Co., Ltd.), rabbit anti-Beclin-1 (1:1,000; cat. no. ab62557; Abcam) and rabbit anti-microtubule-associated protein 1A/1B-light chain 3 (LC3-II; 1:500; cat. no. bs-8878R; BIOSS).

Statistical analysis. All data were expressed as the mean \pm standard deviation with six repeats in both the animal and cell culture experiments. Statistical analysis was carried out with GraphPad Prism 7 (GraphPad Software, Inc.) using one-way ANOVA followed by the Bonferroni test. $\mathrm{P}<0.05$ was considered to indicate a statistically significant difference.

\section{Results}

SP inhibits doxorubicin-induced apoptosis of H9c2 cells. $\mathrm{H} 9 \mathrm{c} 2$ myocardial cells were treated with different concentrations of SP for $24 \mathrm{~h}$. Viability of $\mathrm{H} 9 \mathrm{c} 2$ cells was detected using the CCK- 8 method. SP at concentrations ranging between 0.1 and $1.0 \mu \mathrm{g} / \mathrm{ml}$ did not affect H9c2 cell viability (Fig. 1). By contrast, 5 or $10 \mu \mathrm{g} / \mathrm{ml} \mathrm{SP} \mathrm{significantly} \mathrm{reduced} \mathrm{cell} \mathrm{viability}$ compared with untreated controls.

Using the results of the CCK-8 assay, $1 \mu \mathrm{g} / \mathrm{ml} \mathrm{SP}$ was selected to investigate the effect of SP on doxorubicin-induced injury of H9c2 cells. The apoptosis of H9c2 cells treated with doxorubicin was significantly higher compared with that detected in the control H9c2 cells, whereas SP significantly reduced this effect (Fig. 2).

Effects of SP on the expression levels of Bax, Bcl-2, Beclin-1 and $L C 3$ in doxorubicin-treated $H 9 c 2$ cells. In order to further explore the specific effects of SP on apoptosis and autophagy, the protein expression levels of Bcl-2, Bax, Beclin-1 and LC3 were monitored in H9c2 cells. As shown in Fig. 3, Bcl-2 expression in doxorubicin-treated $\mathrm{H} 9 \mathrm{c} 2$ cells was significantly lower compared with that in the control group, whereas the addition of SP to the doxorubicin-treated cells had no effect on $\mathrm{Bcl}-2$ expression. Bax expression was comparable in all three groups, which indicated that Bax was unaffected by doxorubicin and SP.

Compared with in the control H9c2 cells, doxorubicin treatment reduced the expression levels of Beclin-1 and LC3. SP further reduced Beclin-1 expression, but inhibited the doxorubicin-induced decrease in LC3 (Fig. 3). These data suggested that SP might rescue doxorubicin-induced autophagy dysfunction.

SP increases food intake in rats with heart failure. Of the 12 rats used in the present study, none died during the experiments. Compared with the control rats, the food intake and body weight of the rats in the heart-failure group were significantly decreased (Fig. 4). Administration of SP to the heart-failure rats was associated with no significant change in body weight for 12 days; however, food intake rose on days 10-12.

Subsequently, a six-lead ECG was used to monitor heart function and representative traces are shown in Fig. 5. Heart rate was also quantified in the three groups. Compared with in the control group, heart rate in the heart-failure group was significantly decreased, whereas SP treatment inhibited this decrease (Fig. 5).

Histological observation of rat myocardium. The results of H\&E staining of rat myocardial tissue are shown in Fig. 6 . Compared with in the control group, the cardiomyocytes in the doxorubicin-induced heart-failure group were arranged in a disordered pattern and were loosely connected. SP treatment ameliorated these pathological changes caused by doxorubicin.

Compared with in the control group, cardiomyocytes in the heart-failure group exhibited a loss of striations, vacuolation with damaged organelle, indicating dysfunction of autophagy. By contrast, SP reduced the loss of striations, as well as vacuolation (Fig. 7).

SP reduces cardiomyocyte apoptosis in rats with heart failure. TUNEL staining was used to determine the level of apoptosis in myocardial tissue. Apoptosis in myocardial tissue from the heart-failure group was significantly higher compared with that in the control group, whereas this effect was inhibited by SP treatment (Fig. 8). 

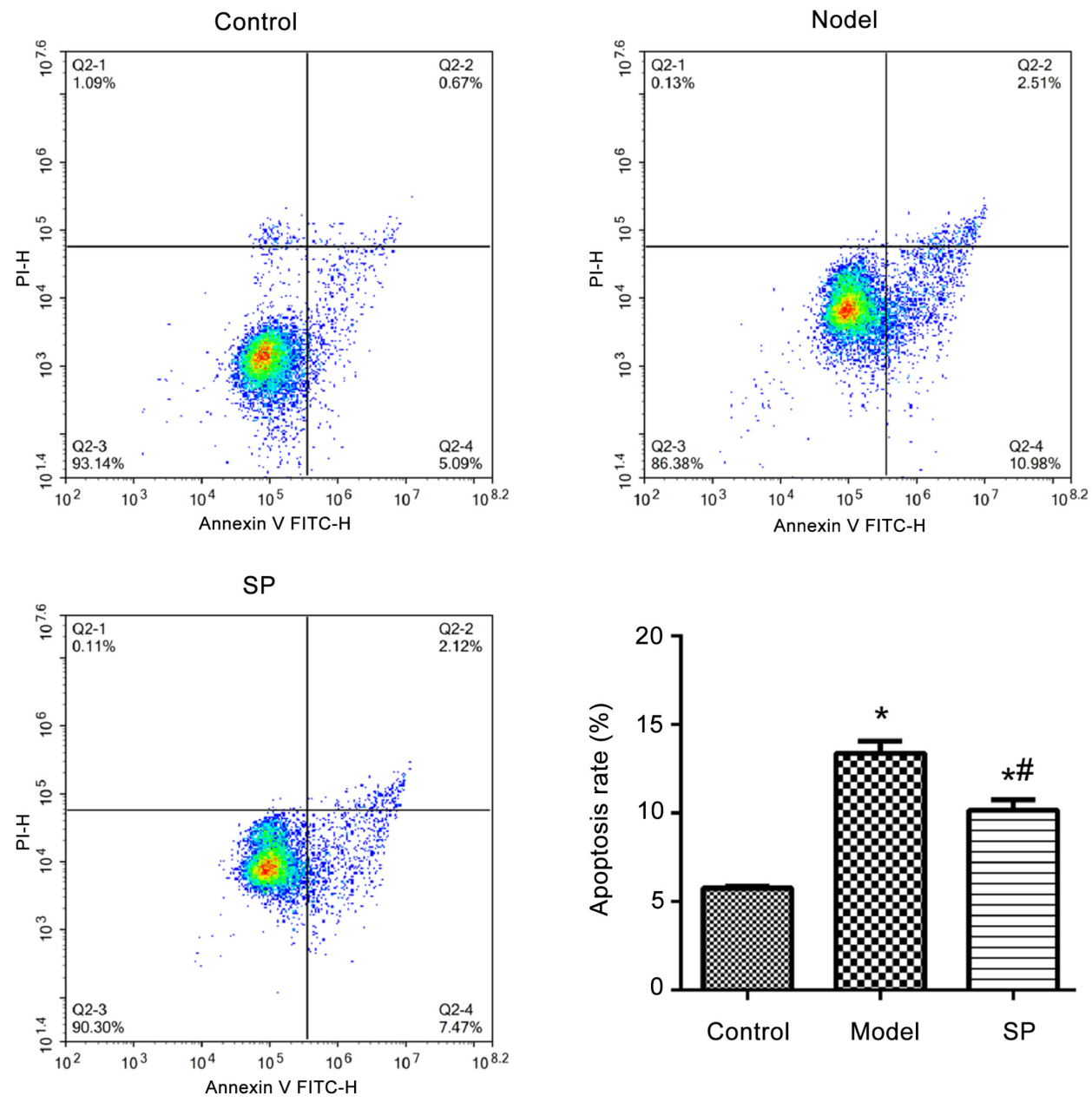

Figure 2. SP inhibits doxorubicin-induced apoptosis of H9c2 cells. Apoptosis of H9c2 cells in the doxorubicin-treated group was higher compared with that in control H9c2 cells, whereas SP attenuated doxorubicin-induced apoptosis. ${ }^{*} \mathrm{P}<0.05$ vs. control cells; ${ }^{\prime \prime} \mathrm{P}<0.05$ vs. model cells ( $\mathrm{n}=6$ repeats/group). SP, substance P.
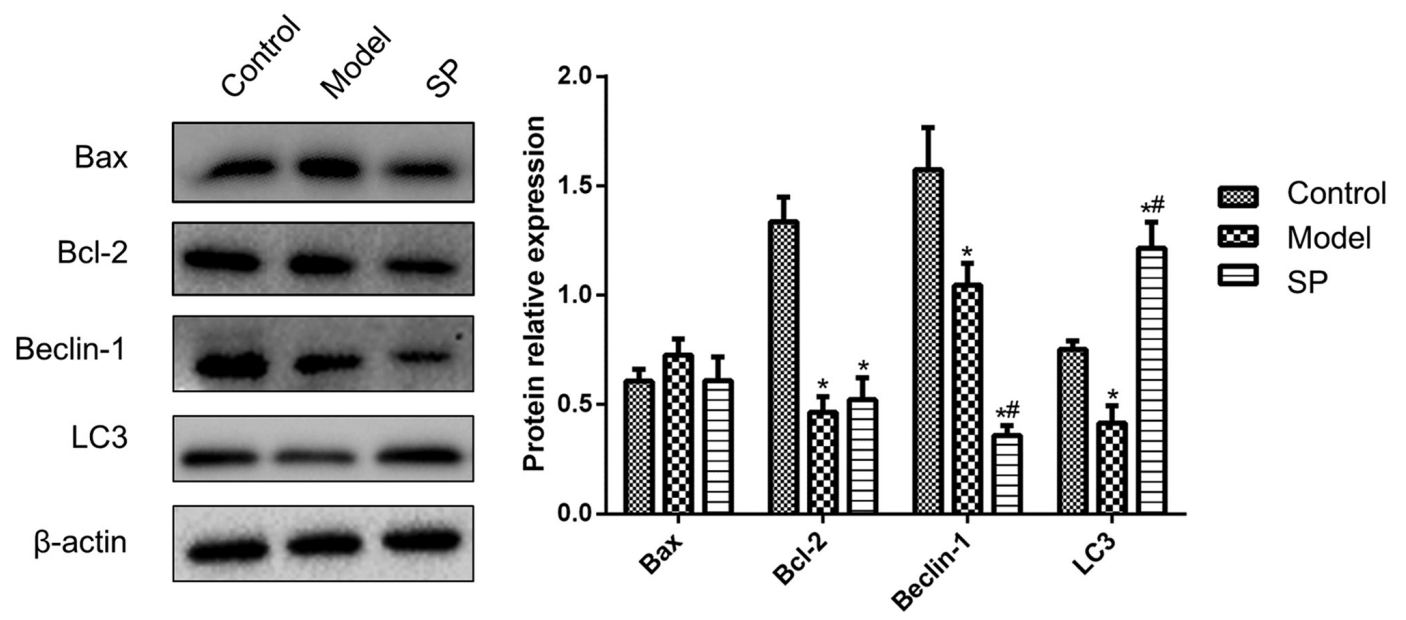

Figure 3. Effects of SP on the expression levels of Bax, Bcl-2, Beclin-1 and LC3 in H9c2 cells. Bcl-2 expression in the doxorubicin-treated group was significantly lower than in the control group, whereas SP did not influence Bcl-2 expression in the doxorubicin-treated group. Doxorubicin reduced the expression levels of Beclin-1 and LC3 in H9c2 cells, whereas SP further reduced Beclin-1 expression, but inhibited the doxorubicin-induced decrease in LC3 levels. ${ }^{*} \mathrm{P}<0.05$ vs. control cells; ${ }^{\mathrm{P}} \mathrm{P}<0.05$ vs. model cells ( $\mathrm{n}=6$ repeats in each group). SP, substance $\mathrm{P}$; Bcl-2, B-cell lymphoma 2; Bax, Bcl-2-associated $\mathrm{X}$ protein; LC3, microtubule-associated protein 1A/1B-light chain 3.

Effects of SP on the expression levels of Bax, Bcl-2, Beclin-1 and LC3 in heart-failure rats. Compared with in the control group, there was a significant decrease in the protein expres- sion levels of Bcl-2, Beclin-1 and LC3, but not Bax, in the heart-failure group (Fig. 9). SP inhibited these changes in LC3, although Beclin-1 expression was further reduced. 
A

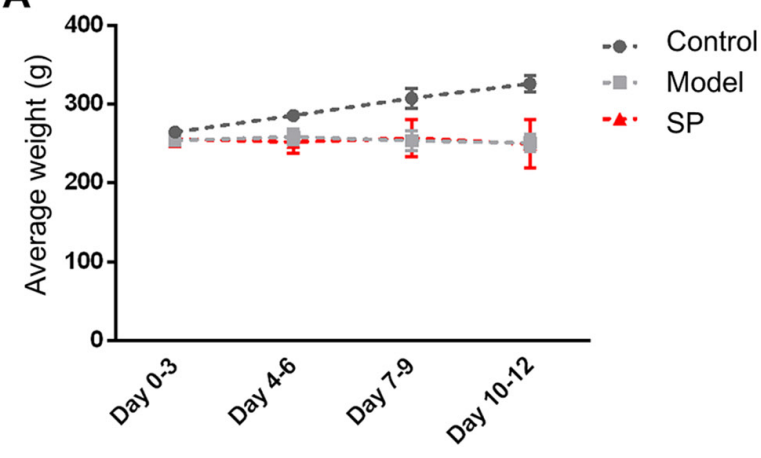

B

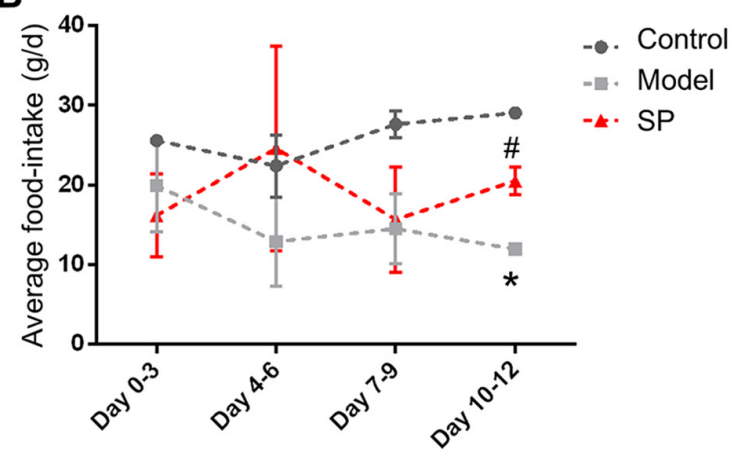

Figure 4. SP increases food intake in rats with heart failure. (A) Rat weight and (B) food intake. Food intake and weight of the rats decreased in the heart-failure group. Administration of $\mathrm{SP}$ increased food intake on days $4-12 .{ }^{~} \mathrm{P}<0.05$ vs. control group; ${ }^{*} \mathrm{P}<0.05$ vs. model group (n=6 repeats/group). SP, substance $\mathrm{P}$.

A

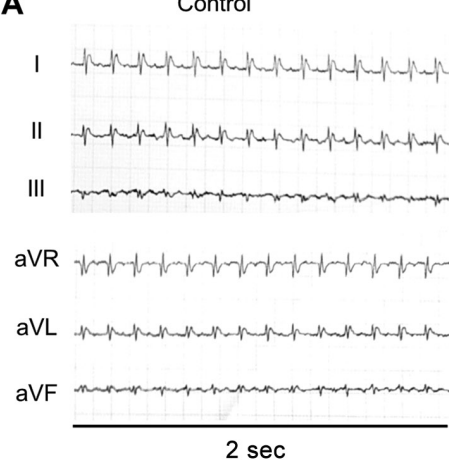

Model
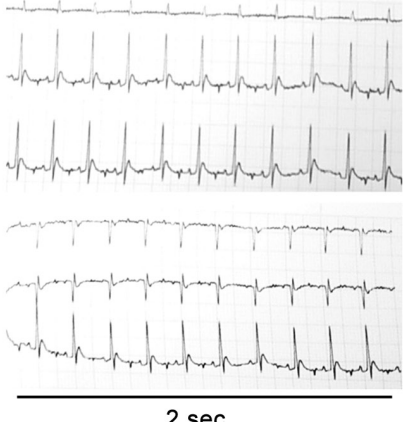

$2 \mathrm{sec}$

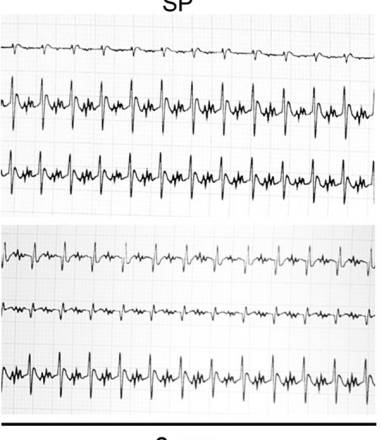

$2 \mathrm{sec}$

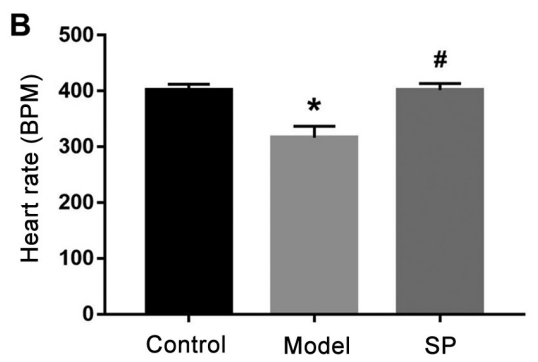

Figure 5. SP ameliorates the impaired heart rate in rats with heart failure. (A) representative ECG traces. (B) Heart rate. ${ }^{*} \mathrm{P}<0.05$ vs. control group; ${ }^{\#} \mathrm{P}<0.05$ vs. model group ( $\mathrm{n}=6$ repeats/group). SP, substance P; BPM, beats per minute; ECG, electrocardiogram.

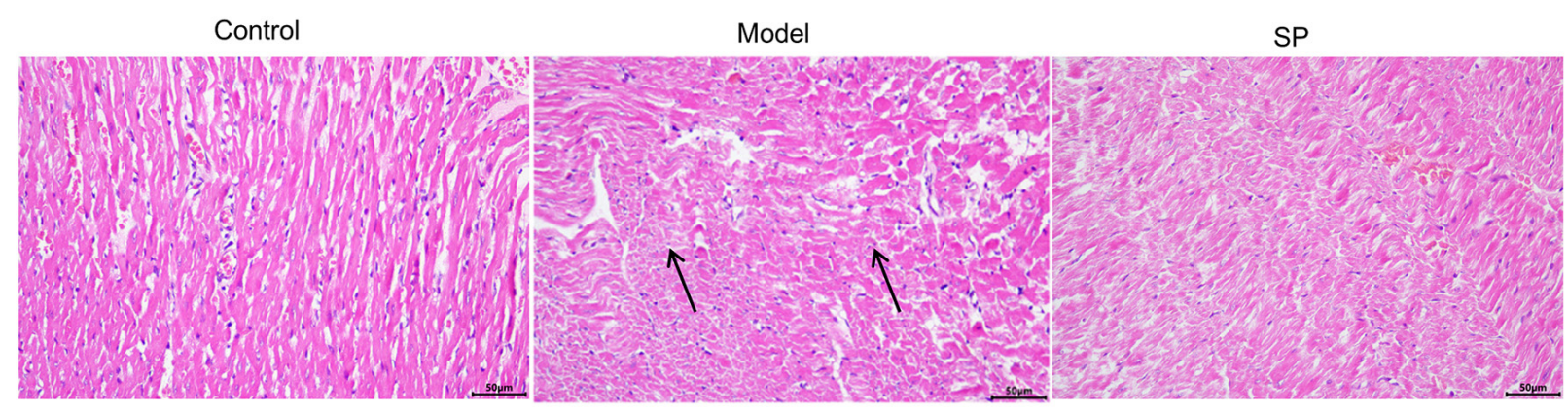

Figure 6. Pathological changes in myocardial tissues. Myocardial fibers were disordered and loose (arrows), and there were more gaps between muscle cells in the heart-failure group. SP treatment remedied the pathological changes caused by doxorubicin. Magnification, x200. SP, substance P.

Additionally, SP increased Bax expression, while it did not affect Bcl-2 expression compared with the model group. These results indicated that SP promoted autophagy, while reducing apoptosis.

\section{Discussion}

In the present study, the rate of apoptosis of $\mathrm{H} 9 \mathrm{c} 2$ cells was increased following doxorubicin treatment. Pathological changes 

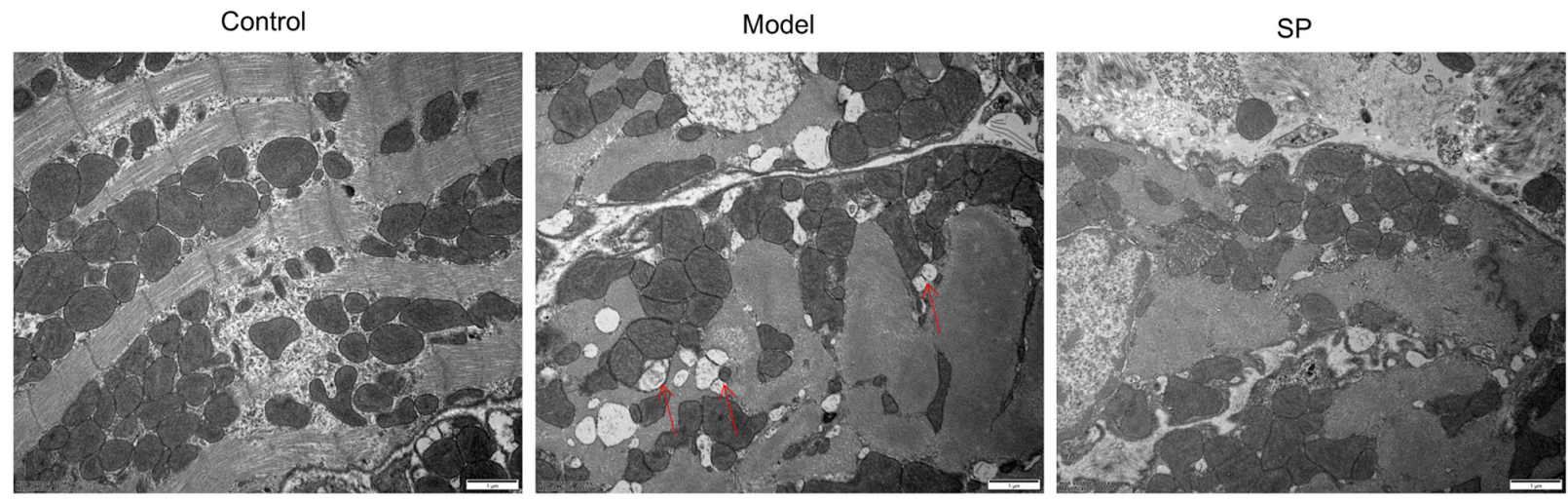

Figure 7. Ultrastructure of cardiomyocytes in the different groups. Cardiomyocytes in the heart-failure model lost striations, became vacuolated and exhibited obvious dysfunction of autophagy. SP promoted autophagy of cardiomyocytes in doxorubicin-induced heart failure. The arrow indicates the accumulated autophagic vacuole. Scale bar, $1 \mu \mathrm{m}$. SP, substance P.
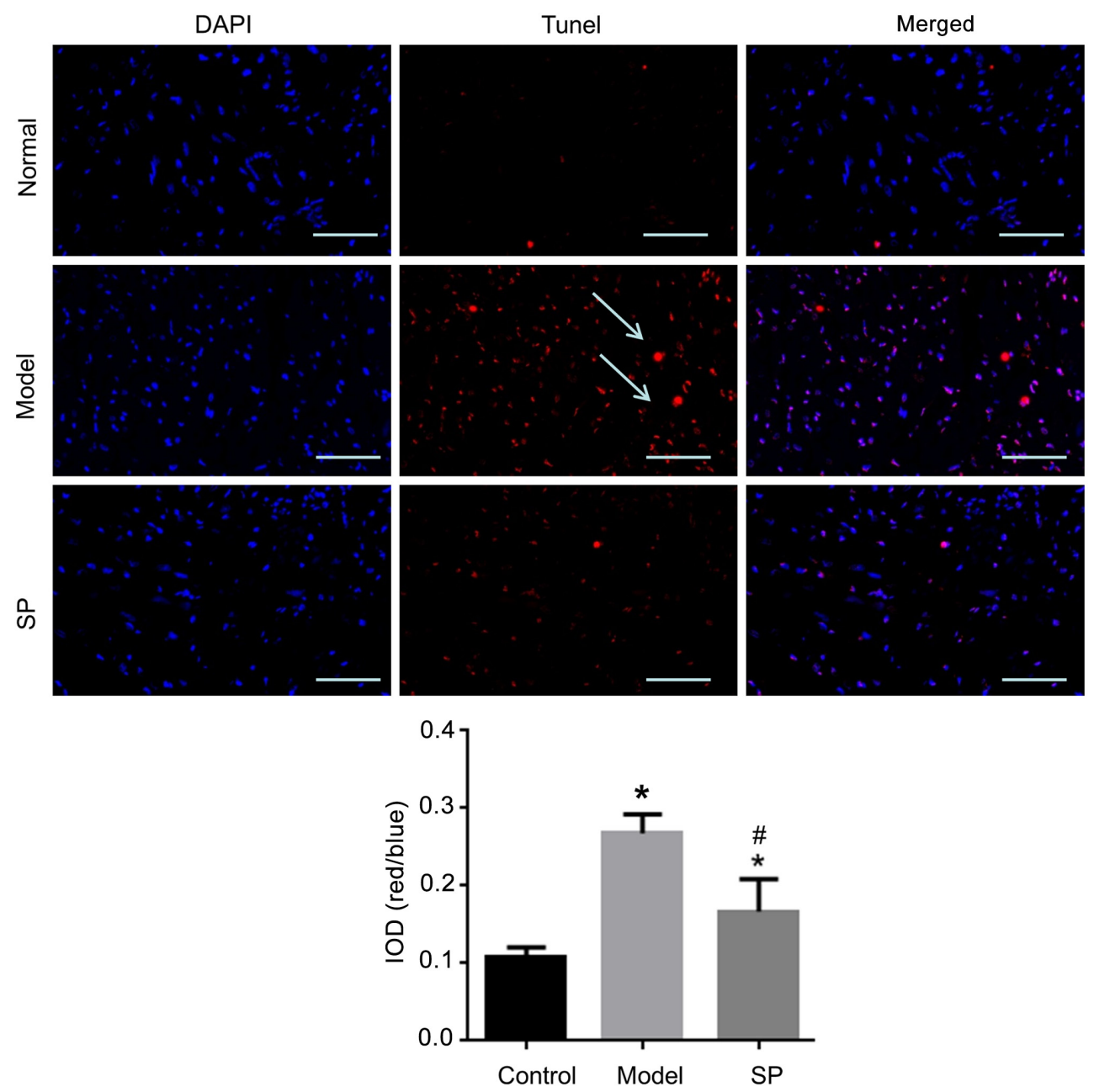

Figure 8. SP reduces cardiomyocyte apoptosis in rats with heart failure. The level of apoptosis in myocardial tissue of the heart-failure group was significantly higher compared with that in the control group, whereas the rate of apoptosis in the SP treatment group was lower compared with in the heart-failure group. The arrow indicates apoptotic cells. Scale bar, $100 \mu \mathrm{m}$. ${ }^{*} \mathrm{P}<0.05$ vs. control group; ${ }^{*} \mathrm{P}<0.05$ vs. model group ( $\mathrm{n}=6$ repeats/group). SP, substance $\mathrm{P} ;$ IOD, integrated optical density.

of myocardial tissue in doxorubicin-treated rats were observed. By contrast, SP protected against doxorubicin-induced injury of H9c2 cells and heart tissue. The present study provided evidence that SP limited apoptosis and triggered autophagy, which potentially has implications for therapeutic applications.
Doxorubicin is a common chemotherapeutic drug, which acts primarily through the induction of apoptosis by inhibiting topoisomerase activity and generating ROS (1).Cardiomyocytes are susceptible to doxorubicin; therefore, cardiotoxicity is a prominent side effect (3), and doxorubicin is widely used to 


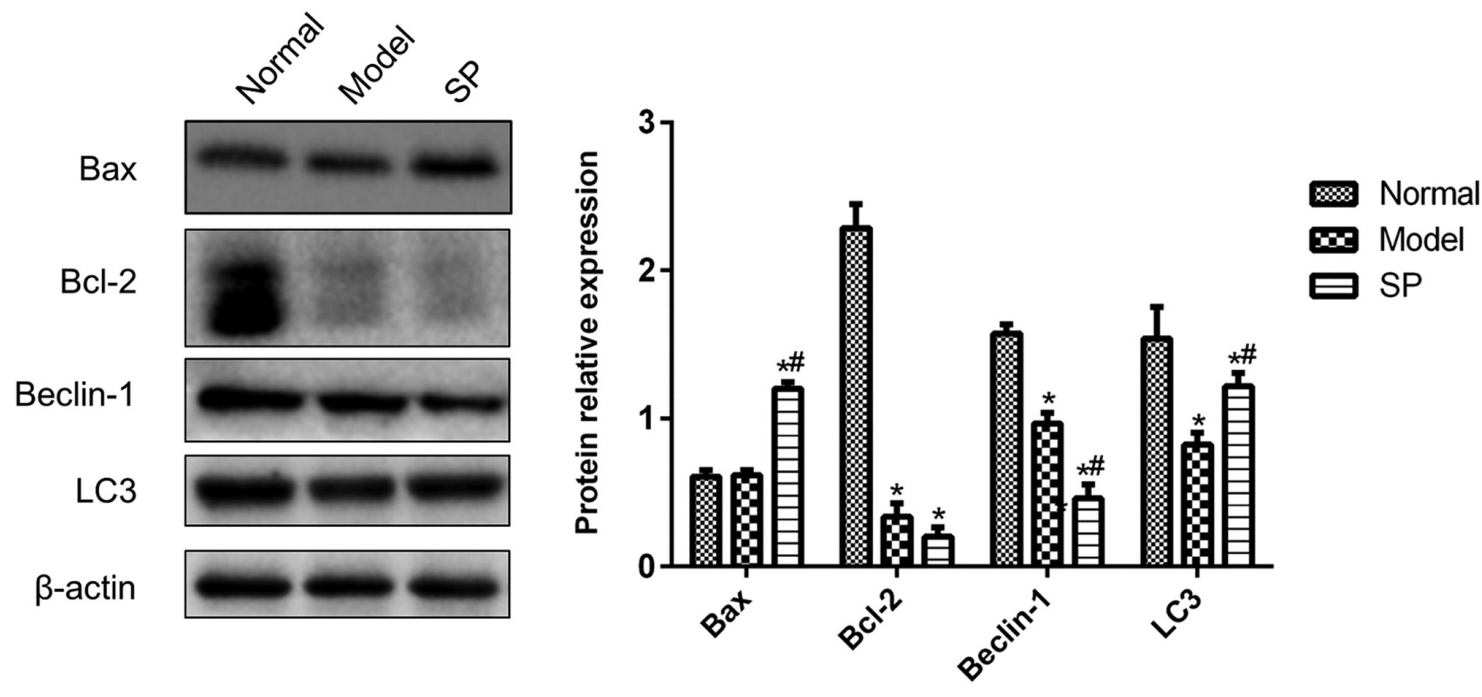

Figure 9. Effects of SP on the expression levels of Bax, Bcl-2, Beclin-1 and LC3 in heart failure rats. The expression levels of Bcl-2, Beclin-1 and LC3 were reduced in the heart-failure model. SP promoted the expression levels of Bax and LC3, and inhibited Beclin-1 expression. *P<0.05 vs. control group; ${ }^{\#} \mathrm{P}<0.05$ vs. model group ( $\mathrm{n}=6$ repeats/group). SP, substance P; Bcl-2, B-cell lymphoma 2; Bax, Bcl-2-associated X protein; LC3, microtubule-associated protein 1A/1B-light chain 3 .

produce animal and cellular models of heart failure $(4,5)$. The present study found that doxorubicin triggered cardiotoxicity, as evidenced by an increase in apoptosis and apoptosis-related protein (Bcl-2) expression. Notably, it was found that a safe concentration of SP prevented doxorubicin-induced apoptosis of H9c2 cells. These data suggested that SP at specific concentrations may prevent doxorubicin-induced cardiotoxicity.

The present study demonstrated that $1 \mu \mathrm{g} / \mathrm{ml} \mathrm{SP}$ had no significant effect on the viability of $\mathrm{H} 9 \mathrm{c} 2$ cells, but reduced doxorubicin-induced apoptosis of $\mathrm{H} 9 \mathrm{c} 2$ cells. In addition, the experimental results demonstrated that doxorubicin could reduce the expression levels of Beclin-1 and LC3 in H9c2 cells, whereas SP further reduced the expression of Beclin-1 but increased the expression of LC3. As the mammalian ortholog of the yeast Atg6 gene, Beclin-1 is an essential mediator of autophagy. In addition, it has also been reported that Beclin 1 may have a proapoptotic role (27). By contrast, LC3 can be used to indicate autophagy (28). Therefore, the present study indicated that SP may promote autophagy and reduce apoptosis.

In the apoptosis cascade, Bcl-2 and Bax balance each other in controlling release of cytochrome $\mathrm{c}$ from mitochondria to determine cell death (29). Therefore, the expression levels of Bcl-2 and Bax are considered to be representative of apoptosis (30). The present study detected Bcl-2 and Bax expression in $\mathrm{H} 9 \mathrm{c} 2$ cells and heart tissue that had experienced doxorubicin-induced injury. It was observed that doxorubicin reduced Bcl-2 expression in vitro and in vivo, whereas it did not affect Bax, which implicated apoptosis in doxorubicin-induced injury of cardiomyocytes $(31,32)$. Notably, SP could reverse the effect of doxorubicin on the $\mathrm{Bcl}-2 / \mathrm{Bax}$ ratio. These data further support the conclusion that SP can prevent doxorubicin-induced apoptosis of cardiomyocytes.

The present study also investigated the effects of SP on food intake and body weight in rats with heart failure. The data demonstrated that SP could increase food intake following heart failure. Reduction of heart rate is an important functional index of heart failure (33). The present study used an ECG to monitor heart function. Heart rate was reduced in model group, indicating the heart function was impaired. By contrast, SP could reduce the impairment. The results of H\&E staining also suggested that SP could repair doxorubicin-induced morphological changes in heart tissue. Taken together, these data support the conclusion that SP can block doxorubicin-induced heart malfunction.

Autophagy is considered to be an important mechanism of organelle and protein turnover in cells (20). Autophagy can prevent apoptosis in cases of mild external stimulation, and the activation of apoptosis-related caspase-3 can block autophagy (34-36). The present findings indicated that SP could reduce doxorubicin-induced cardiomyocyte apoptosis by increasing autophagy in myocardial tissue, which suggested a potential for SP in the treatment of heart failure.

The data in the present study contradicted some earlier publications $(37,38)$ in which SP antagonists inhibited doxorubicin-induced cardiomyocyte apoptosis and triple-negative breast cancer chemoresistance. These discrepancies might be caused in part by bidirectional regulation of SP signaling pathways, as discussed in a previous review in which SP was shown to have beneficial as well as detrimental effects on heart failure (39). The duration and dose of SP might also control its various functions. The present study revealed that high doses of SP were detrimental to H9c2 cells, whereas low doses exerted protection against doxorubicin-induced cardiomyocyte injury. This observation might have important implications for clinical applications of SP and warrants further investigation.

The present study demonstrated a mechanism by which SP reduced cardiomyocyte apoptosis in doxorubicin-induced cardiomyocyte injury, potentially by promoting autophagy. However, the effects of SP on doxorubicin-induced oxidative stress deserve future investigation. Additionally, the direct relationship between apoptosis and autophagy still requires investigation. 
In conclusion, the present study indicated that SP reduced cardiomyocyte apoptosis, potentially by promoting autophagy, in a rat model of doxorubicin-induced heart failure, which indicated that SP might be a potential therapeutic substance for heart failure.

\section{Acknowledgements}

Not applicable.

\section{Funding}

This work was supported by the Jiangxi Science and Technology Project (grant no. 20192BBGL70031).

\section{Availability of data and materials}

The datasets used and/or analyzed during the current study are available from the corresponding author on reasonable request.

\section{Authors' contributions}

FXC, QW, QLL, JF and LP performed the experiments and analyzed the data. FC and JH designed the study, wrote the manuscript and confirm the authenticity of all the raw data. All authors have read and approved the final manuscript.

\section{Ethics approval and consent to participate}

All experimental procedures were approved by the Ethics Committee of People's Hospital Affiliated to Nanchang University (Nanchang, China; approval no. 2019-037).

\section{Patient consent for publication}

Not applicable.

\section{Competing interests}

The authors declare that they have no competing interests.

\section{References}

1. Taheri M, Mahmud Hussen B, Tondro Anamag F, Shoorei H, Dinger ME and Ghafouri-Fard S: The role of miRNAs and IncRNAs in conferring resistance to doxorubicin. J Drug Target: Apr 15, 2021 (Epub ahead of print.).

2. Conklin KA: Chemotherapy-associated oxidative stress: Impact on chemotherapeutic effectiveness. Integr Cancer Ther 3: 294-300, 2004

3. Shabalala S, Muller CJF, Louw J and Johnson R: Polyphenols, autophagy and doxorubicin-induced cardiotoxicity. Life Sci 180: 160-170, 2017.

4. Mitry MA and Edwards JG: Doxorubicin induced heart failure: Phenotype and molecular mechanisms. Int J Cardiol Heart Vasc 10: 17-24, 2016.

5. Jiang Y, Liu Y, Xiao W, Zhang D, Liu X, Xiao H, You S and Yuan L: Xinmailong attenuates doxorubicin-induced lysosomal dysfunction and oxidative stress in $\mathrm{H} 9 \mathrm{c} 2$ cells via HO-1. Oxid Med Cell Longev 2021: 5896931, 2021.

6. Narula J, Haider N, Arbustini E and Chandrashekhar Y: Mechanisms of disease: Apoptosis in heart failure - seeing hope in death. Nat Clin Pract Cardiovasc Med 3: 681-688, 2006.

7. van Empel VP, Bertrand AT, Hofstra L, Crijns HJ, Doevendans PA and De Windt LJ: Myocyte apoptosis in heart failure. Cardiovasc Res 67: 21-29, 2005.
8. Pennefather JN, Lecci A, Candenas ML, Patak E, Pinto FM and Maggi CA: Tachykinins and tachykinin receptors: A growing family. Life Sci 74: 1445-1463, 2004.

9. Brain SD and Cox HM: Neuropeptides and their receptors: Innovative science providing novel therapeutic targets. Br J Pharmacol 147 (Suppl 1): S202-S211, 2006.

10. Massaad CA, Safieh-Garabedian B, Poole S, Atweh SF, Jabbur SJ and Saadé NE: Involvement of substance P, CGRP and histamine in the hyperalgesia and cytokine upregulation induced by intraplantar injection of capsaicin in rats. J Neuroimmunol 153: 171-182, 2004

11. Vergnolle N, Bunnett NW, Sharkey KA, Brussee V, Compton SJ, Grady EF, Cirino G, Gerard N, Basbaum AI, Andrade-Gordon $\mathrm{P}$, et al: Proteinase-activated receptor-2 and hyperalgesia: A novel pain pathway. Nat Med 7: 821-826, 2001.

12. Meléndez GC, Li J, Law BA, Janicki JS, Supowit SC and Levick SP: Substance P induces adverse myocardial remodelling via a mechanism involving cardiac mast cells. Cardiovasc Res 92: 420-429, 2011.

13. Johnson MB, Young AD and Marriott I: The Therapeutic potential of targeting substance P/NK-1R interactions in inflammatory CNS disorders. Front Cell Neurosci 10: 296, 2017.

14. Hua F, Ricketts BA, Reifsteck A, Ardell JL and Williams CA: Myocardial ischemia induces the release of substance $\mathrm{P}$ from cardiac afferent neurons in rat thoracic spinal cord. Am J Physiol Heart Circ Physiol 286: H1654-H1664, 2004.

15. Wang LL, Guo Z, Han Y, Wang PF, Zhang RL, Zhao YL, Zhao FP and Zhao XY: Implication of Substance P in myocardial contractile function during ischemia in rats. Regul Pept 167: 185-191, 2011.

16. Amadesi S, Reni C, Katare R, Meloni M, Oikawa A, Beltrami AP, Avolio E, Cesselli D, Fortunato O, Spinetti G, et al: Role for substance p-based nociceptive signaling in progenitor cell activation and angiogenesis during ischemia in mice and in human subjects. Circulation 125: 1774-1786, S1-S9, 2012.

17. Robinson P, Garza A, Moore J, Eckols TK, Parti S, Balaji V, Vallejo $\mathrm{J}$ and Tweardy DJ: Substance $\mathrm{P}$ is required for the pathogenesis of EMCV infection in mice. Int J Clin Exp Med 2: 76-86, 2009.

18. Mak IT, Chmielinska JJ, Kramer JH, Spurney CF and Weglicki WB: Loss of neutral endopeptidase activity contributes to neutrophil activation and cardiac dysfunction during chronic hypomagnesemia: Protection by substance $\mathrm{P}$ receptor blockade. Exp Clin Cardiol 16: 121-124, 2011.

19. Cury PR, Canavez F, de Araújo VC, Furuse C and de Araújo NS: Substance P regulates the expression of matrix metalloproteinases and tissue inhibitors of metalloproteinase in cultured human gingival fibroblasts. J Periodontal Res 43: 255-260, 2008.

20. Zhu G, Wang X, Wu S, Li X and Li Q: Neuroprotective effects of puerarin on 1-methyl-4-phenyl-1,2,3,6-tetrahydropyridine induced Parkinson's disease model in mice. Phytother Res 28: 179-186, 2014.

21. Yang Y and Klionsky DJ: Autophagy and disease: Unanswered questions. Cell Death Differ 27: 858-871, 2020.

22. Levine B and Kroemer G: Autophagy in the pathogenesis of disease. Cell 132: 27-42, 2008.

23. Wu X, Zhang N, Kan J, Tang S, Sun R, Wang Z, Chen M, Liu J and Jin C: Polyphenols from Arctium lappa L ameliorate doxorubicin-induced heart failure and improve gut microbiota composition in mice. J Food Biochem: Apr 17, 2021 (Epub ahead of print).

24. Piao J, Park JS, Hwang DY, Son Y and Hong HS: Substance P blocks ovariectomy-induced bone loss by modulating inflammation and potentiating stem cell function. Aging (Albany NY) 12: 20753-20777, 2020.

25. Zhang Z, Song Z, Shen F, Xie P, Wang J, Zhu AS and Zhu G: Ginsenoside $\operatorname{Rg} 1$ prevents PTSD-like behaviors in mice through promoting synaptic proteins, reducing Kir4.1 and TNF- $\alpha$ in the hippocampus. Mol Neurobiol 58: 1550-1563, 2021.

26. Shen F, Song Z, Xie P, Li L, Wang B, Peng D and Zhu G: Polygonatum sibiricum polysaccharide prevents depression-like behaviors by reducing oxidative stress, inflammation, and cellular and synaptic damage. J Ethnopharmacol 275: 114164, 2021.

27. Huang X, Qi Q, Hua X, Li X, Zhang W, Sun H, Li S, Wang X and Li B: Beclin 1, an autophagy-related gene, augments apoptosis in U87 glioblastoma cells. Oncol Rep 31: 1761-1767, 2014.

28. Runwal G, Stamatakou E, Siddiqi FH, Puri C, Zhu Y and Rubinsztein DC: LC3-positive structures are prominent in autophagy-deficient cells. Sci Rep 9: 10147, 2019. 
29. Wang Q, Zhang L, Yuan X, Ou Y, Zhu X, Cheng Z, Zhang P, Wu X, Meng Y and Zhang L: The Relationship between the $\mathrm{Bcl}-2 / \mathrm{Bax}$ proteins and the mitochondria-mediated apoptosis pathway in the differentiation of adipose-derived stromal cells into neurons. PLoS One 11: e0163327, 2016.

30. Wang X, Xu W, Chen H, Li W, Li W and Zhu G: Astragaloside IV prevents Abeta1-42 oligomers-induced memory impairment and hippocampal cell apoptosis by promoting PPARgamma/BDNF signaling pathway. Brain Res 147041: 2020, 1747.

31. Korsmeyer SJ, Shutter JR, Veis DJ, Merry DE and Oltvai ZN: Bcl-2/Bax: A rheostat that regulates an anti-oxidant pathway and cell death. Semin Cancer Biol 4: 327-332, 1993.

32. Andreu-Fernández V, Sancho M, Genovés A, Lucendo E, Todt F, Lauterwasser J, Funk K, Jahreis G, Pérez-Payá E, Mingarro I, et al: Bax transmembrane domain interacts with prosurvival Bcl-2 proteins in biological membranes. Proc Natl Acad Sci USA 114: 310-315, 2017.

33. Wu S, Cao J, Zhang T, Zhou Y, Wang K, Zhu G and Zhou M: Electroacupuncture ameliorates the coronary occlusion related tachycardia and hypotension in acute rat myocardial ischemia model: potential role of hippocampus. Evid Based Complement Alternat Med 2015: 925987, 2015.

34. Youle RJ and Narendra DP: Mechanisms of mitophagy. Nat Rev Mol Cell Biol 12: 9-14, 2011.
35. Pagliarini V, Wirawan E, Romagnoli A, Ciccosanti F, Lisi G, Lippens S, Cecconi F, Fimia GM, Vandenabeele P, Corazzari M, et al: Proteolysis of Ambral during apoptosis has a role in the inhibition of the autophagic pro-survival response. Cell Death Differ 19: 1495-1504, 2012.

36. Mariño G, Niso-Santano M, Baehrecke EH and Kroemer G: Self-consumption: The interplay of autophagy and apoptosis. Nat Rev Mol Cell Biol 15: 81-94, 2014.

37. Legi A, Rodriguez E, Eckols TK, Mistry C and Robinson P: Substance $\mathrm{P}$ antagonism prevents chemotherapy-induced cardiotoxicity. Cancers (Basel) 13: 1732, 2021.

38. Robinson P, Kasembeli M, Bharadwaj U, Engineer N, Eckols KT, Tweardy DJ and Substance P: Substance P receptor signaling mediates doxorubicin-induced cardiomyocyte apoptosis and triple-negative breast cancer chemoresistance. BioMed Res Int 2016: 1959270, 2016.

39. Dehlin HM and Levick SP: Substance P in heart failure: The good and the bad. Int J Cardiol 170: 270-277, 2014

This work is licensed under a Creative Commons Attribution-NonCommercial-NoDerivatives 4.0 International (CC BY-NC-ND 4.0) License. 